\title{
Porphyrinoids
}

\section{Global Aromaticity and Antiaromaticity in Porphyrin Nanoring Anions**}

\author{
Martin D. Peeks, Michael Jirasek, Timothy D. W. Claridge, and Harry L. Anderson*
}

\begin{abstract}
Doping, through oxidation or reduction, is often used to modify the properties of $\pi$-conjugated oligomers. In most cases, the resulting charge distribution is difficult to determine. If the oligomer is cyclic and doping establishes global aromaticity or antiaromaticity, then it is certain that the charge is fully delocalized over the entire perimeter of the ring. Herein we show that reduction of a six-porphyrin nanoring using decamethylcobaltocene results in global aromaticity (in the 6- state; $[90 \pi]$ ) and antiaromaticity (in the 4- state; [88 $]$ ]), consistent with the Hückel rules. Aromaticity is assigned by NMR spectroscopy and density-functional theory calculations.
\end{abstract}

Aromaticity is one of the oldest concepts in chemistry, and it is widely used to predict the properties of unsaturated cyclic molecules. ${ }^{[1]}$ In essence, aromaticity describes the anomalous stability of certain molecules, and their peculiarly large anisotropic diamagnetic susceptibilities. ${ }^{[2]}$ This unusual diamagnetism results from the tendency of aromatic molecules to sustain a ring current when placed in a magnetic field. This effect is easily detected by NMR spectroscopy, but aromatic ring currents were first postulated by Pauling and Lonsdale before NMR spectroscopy had been invented. ${ }^{[3]}$ While the earliest aromatic molecules were flat symmetric carbocyclic $\pi$-systems, the concept has been extended to $\sigma$-bonded systems, metal clusters, excited states, twisted molecules, and other systems. ${ }^{[4-6]}$

Hückel's calculations predict that an annulene $\left(\mathrm{C}_{n} \mathrm{H}_{n}\right)$ with a conjugated circuit of $[4 n+2] \pi$-electrons will be aromatic. ${ }^{[7]}$ Breslow extended this rule to state that annulenes

[*] Dr. M. D. Peeks, M. Jirasek, Prof. T. D. W. Claridge,

Prof. H. L. Anderson

Department of Chemistry, University of Oxford

Chemistry Research Laboratory

Oxford, OX1 3TA (UK)

E-mail: harry.anderson@chem.ox.ac.uk

Homepage: http://hla.chem.ox.ac.uk/

Dr. M. D. Peeks

School of Chemistry, University of New South Wales Sydney NSW 2052 (Australia)

[***] A previous version of this manuscript has been deposited on a preprint server (https://doi.org/10.26434/chemrxiv.9120974.v1).

을 Supporting information and the ORCID identification number(s) for

(D) the author(s) of this article can be found under: https://doi.org/10.1002/anie.201909032.

of (C) 2019 The Authors. Published by Wiley-VCH Verlag GmbH \& Co. $\mathrm{KGaA}$. This is an open access article under the terms of the Creative Commons Attribution License, which permits use, distribution and reproduction in any medium, provided the original work is properly cited. with $[4 n] \pi$-electrons are antiaromatic, with reduced stability and the opposite ring currents (paratropic rather than diatropic).$^{[8]}$ Although Hückel's original calculations were restricted to all-carbon, monocyclic annulenes, the rules also apply to a wide range of heterocyclic and polycyclic molecules. However, there are many macrocyclic $\pi$-conjugated rings with $[4 n+2]$ or $[4 n] \pi$-electrons that do not display global aromatic or antiaromatic ring currents. For example, cycloparaphenylenes $([n] \mathrm{CPPs}$, Figure 1$)$ have $[4 n] \pi$-elec-

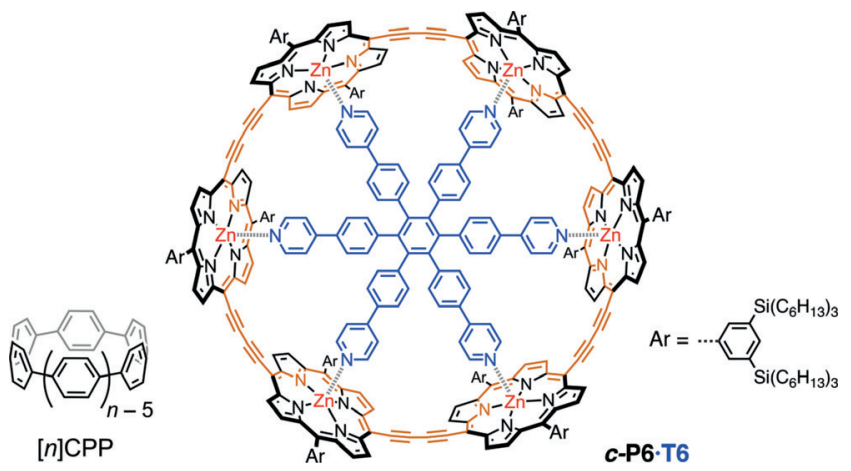

Figure 1. Examples of $\pi$-conjugated macrocycles: [ $n]$ cycloparaphenylenes ([n]CPPs), and a six-porphyrin nanoring, $\boldsymbol{c}$-P6.T6 (template T6 in blue; conjugated circuit in orange).

trons in their circumferential conjugation path, yet are nonaromatic in their electronically neutral ground states. ${ }^{[9]}$ Similarly, butadiyne-linked porphyrin nanorings, such as c-P6.T6, do not exhibit global (anti)aromaticity in their neutral states. ${ }^{[10-12]}$ These macrocycles consist of aromatic subunits, and the local aromaticity of the subunit dominates in the neutral ground states. (Anti)aromaticity can be induced by perturbing the electronic structure, for example, by oxidation or excitation. The removal of two electrons from [8]CPP leads to global aromaticity (30 $\pi$-electrons). ${ }^{[9]}$ Removal of 4 or 6 electrons from the six-porphyrin nanoring c-P6.T6 leads to macrocyclic global antiaromaticity (80 $\pi$ electrons) or aromaticity (78 $\pi$-electrons), respectively. ${ }^{[13]}$ Electronic excitation can lead to excited-state aromaticity, ${ }^{[4,14]}$ and molecules such as $\boldsymbol{c}$-P6 are aromatic in their lowest excited states. ${ }^{[15]}$ Many other macrocycles with global aromaticity in the neutral, cationic, and excited states have been reported in the last decade. ${ }^{[16-21]}$

Porphyrin oligomers have an exceptionally wide range of accessible oxidation states; for example, $\boldsymbol{c}$-P6.T6 can be reversibly oxidized up to the $12+$ state and reduced to the $6-$ state. ${ }^{[13,22]}$ Herein we demonstrate that global ring currents can also be established by reduction. We show that the 
tetraanion is antiaromatic ( $88 \pi$-electrons), and the hexaanion is aromatic (90 $\pi$-electrons). The chemical reduction of annulenes was widely explored during the $1980 \mathrm{~s},{ }^{[23]}$ but there are few recent examples of macrocycles that become aromatic in anionic reduced states, ${ }^{[19]}$ and it was not clear whether this strategy could be used in complex heterocyclic macrocycles, such as porphyrin nanorings.

We began this study by using computational techniques to predict the (anti)aromaticity in reduced states of $\boldsymbol{c}$-P6·T6. The nucleus-independent chemical shift (NICS) ${ }^{[24]}$ which evaluates the chemical shift at a point in space, was calculated using density functional theory (DFT, B3LYP/6-31+G*) for the template-free $\boldsymbol{c}$-P6. The diatropic ring currents of aromatic molecules generate an induced field that opposes the external magnetic field inside the ring, thus leading to a shielding effect and lower chemical shifts. Outside the ring, the induced field reinforces the applied field, leading to NMR deshielding. The paratropic ring currents of antiaromatic molecules have the opposite NMR effects. Therefore, a negative NICS inside the nanoring indicates aromaticity, and a positive NICS indicates antiaromaticity.

The results of NICS calculations (Figure 2 and Table 1) are consistent with predictions from the Hückel rule: the 4state is antiaromatic $\left(\operatorname{NICS}(0)_{\text {iso }}=89 \mathrm{ppm}\right)$, and the $6-$ state is aromatic $\left(\mathrm{NICS}(0)_{\text {iso }}=-13 \mathrm{ppm}\right)$. These NICS values are similar to those calculated previously for the $4+$ and $6+$ oxidation states. ${ }^{[13]}$ The prediction of aromaticity in the $6-$ state is consistent across other functionals (M06-2X and $\omega \mathrm{B} 97 \mathrm{XD}$; see Table S1 in the Supporting Information). The 4- state undergoes symmetry breaking from $D_{6 h}$ to approximate $C_{2 v}$ symmetry, reflecting the pseudo-Jahn-Teller distortion common to antiaromatic molecules. The functionals M06-2X and $\omega$ B97XD predict greater ellipticity than B3LYP (see Table S2), and corresponding lower NICS values (see

Table 1: Nucleus-independent chemical shifts for $\boldsymbol{c}-\mathrm{P} 6$ as a function of oxidation state, at B3LYP/6-31 + G*.

\begin{tabular}{lllrrr}
\hline & Neutral & $4-$ & $6-$ & $4+{ }^{[\mathrm{a}]}$ & $6+{ }^{[\mathrm{a}]}$ \\
\hline$n \pi \mathrm{e}^{-}$ & 84 & 88 & 90 & 80 & 78 \\
$\operatorname{NICS}(0)_{\text {iso }}$ & -1.5 & 88.7 & -13 & 101 & -13 \\
\hline
\end{tabular}

[a] Data from ref. [13].
Table S1). Calculations of the anisotropy of the induced current density (ACID) confirm the conclusions from the NICS calculations (see Figure S3). ${ }^{[25]}$

Square-wave voltammetry of $\boldsymbol{c}$-P6.T6 revealed six reversible reductions in the window -1.30 to $-1.80 \mathrm{~V}$ (vs. Fc/ $\left.\mathrm{Fc}^{+}\right){ }^{[22]}$ There are few reducing agents available in this potential range. ${ }^{[26]}$ Alkali metals are strong reducing agents, but it is difficult to titrate them to avoid over- or underreduction. Therien and co-workers used decamethylcobaltocene $\left(\mathrm{CoCp}_{2}{ }_{2}\right)$ to prepare radical anions of linear porphyrin oligomers. ${ }^{[27]} \mathrm{CoCp}_{2}{ }_{2}$ is a convenient reducing agent because it is sufficiently soluble in THF, and it has an oxidation potential of $-1.84 \mathrm{~V}$ vs. $\mathrm{Fc} / \mathrm{Fc}^{+},{ }^{[26]}$ making it strong enough to access the 6- oxidation state of $\boldsymbol{c}$-P6.T6.

Addition of excess $\mathrm{CoCp}^{*}{ }_{2}$ to a solution of $\boldsymbol{c}$-P6-T6 in $\left[\mathrm{D}_{8}\right]$ THF resulted in a red-brown solution with a fairly well resolved ${ }^{1} \mathrm{H}$ NMR spectrum corresponding to $\boldsymbol{c}$-P6.T6 ${ }^{\mathbf{6}-}$. Addition of $\left[\mathrm{D}_{5}\right]$ pyridine ( $5 \%$ by volume of solvent) resulted in a slightly sharper spectrum (Figure $3 \mathrm{c}$ ). Reduction was reversible and the addition of ferrocenium hexafluorophosphate cleanly regenerated $\boldsymbol{c}$-P6-T6 (see Figure S7). Addition of 4 equivalents of $\mathrm{CoCp}_{2}{ }_{2}$ to neutral $\boldsymbol{c}$-P6.T6 gave the $4-$ state, characterized by a broad chemical-shift dispersion (signals up to $18 \mathrm{ppm}$, Figure $3 \mathrm{~b}$ ). Before assigning the ${ }^{1}$ H NMR spectra of $\boldsymbol{c}$-P6. $\mathbf{T 6}{ }^{4-}$ and $\boldsymbol{c}$-P6. $\mathbf{T 6}^{\mathbf{6}}{ }^{-}$, it is helpful to recapitulate the assignment of neutral $\boldsymbol{c}$-P6-T6 (Figure $3 \mathrm{a}$ ). The protons of the solubilizing trihexylsilyl groups $\left(\mathrm{THS}_{\mathrm{i}}\right.$ and $\mathrm{THS}_{\mathrm{o}}$ for those pointing inside and outside the ring, respectively) give rise to a broad overlapping set of peaks around $1 \mathrm{ppm}$. The porphyrin $\beta$-pyrrole hydrogen atoms (labeled $\mathrm{a}$ and $\mathrm{b}$ in Figure 3) resonate at $\delta=9.6$ and $8.8 \mathrm{ppm}$, respectively, and the proton resonances of the meso-aryl groups (labeled $o_{\mathrm{o}}, o_{\mathrm{i}}$, and $p$ ) appear in the expected region for aromatic signals $(\delta=8.1-8.4 \mathrm{ppm})$. In contrast, the template protons $(\alpha, \beta, \gamma$, and $\delta$ ) are substantially (up to $6 \mathrm{ppm}$ ) shielded by their axial coordination to the porphyrin subunits, which are each locally aromatic.

The global ring current around the nanoring can be evaluated by comparing the shielding inside and outside the nanoring (i.e. THS $\mathrm{v}_{\mathrm{v}}$ vs. THS $\mathrm{T}_{\mathrm{o}}$ and $o_{\mathrm{i}}$ vs. $o_{\mathrm{o}}$ ). The resonances of the template protons $(\alpha, \beta, \gamma$, and $\delta)$ in $\boldsymbol{c}$-P6.T6 ${ }^{6-}$ are readily identified at approximately $4-5 \mathrm{ppm}$ by comparison with the
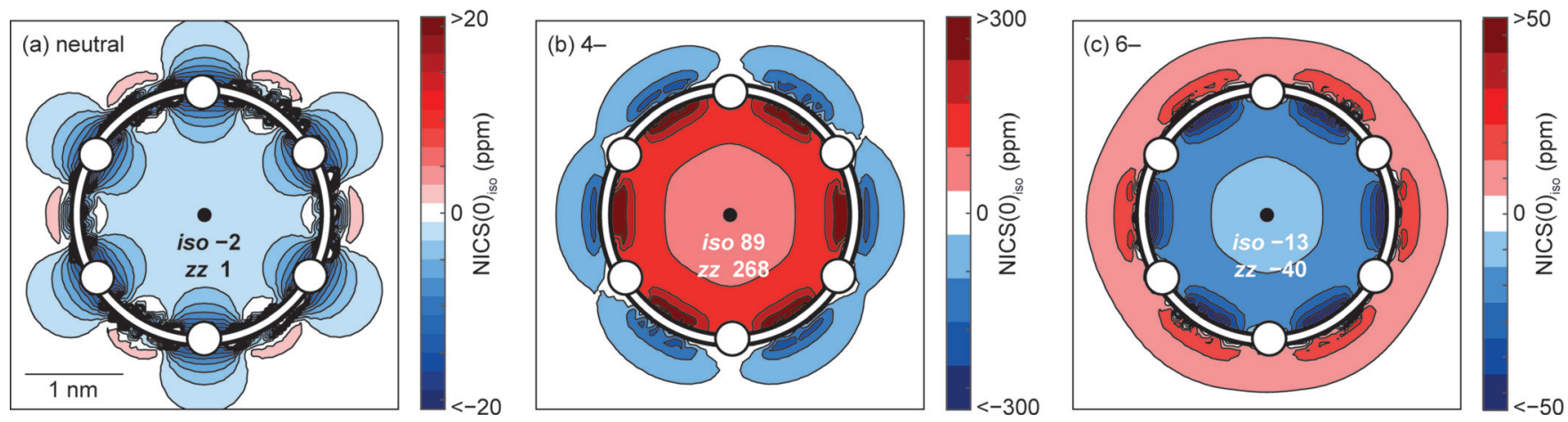

Figure 2. $\mathrm{NICS}(0)_{\text {iso }}$ grids for $c-\mathrm{P} 6$ at the B $3 \mathrm{LYP} / 6-31+\mathrm{G} *$ level of theory: a) neutral; b) $4-$ state; c) $6-$ state. The location of porphyrin subunits is indicated by white circles. The NICS $(0)_{\text {iso }}$ and $\mathrm{NICS}(0)_{z z}$ values at the centers of the rings are indicated at the center of each plot. Further NICS grids and results from other levels of theory are available in the Supporting Information (see Table S1 and Figures S1 and S2). 


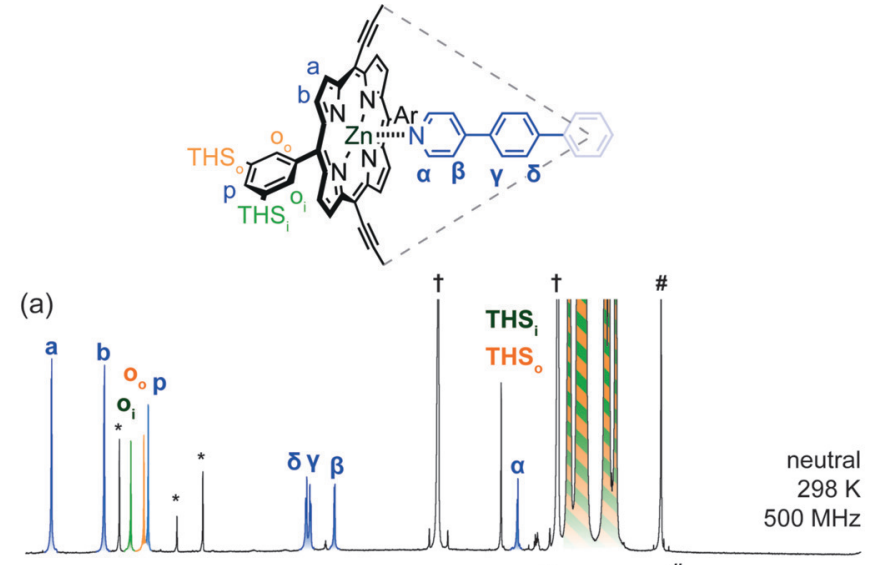

(b)

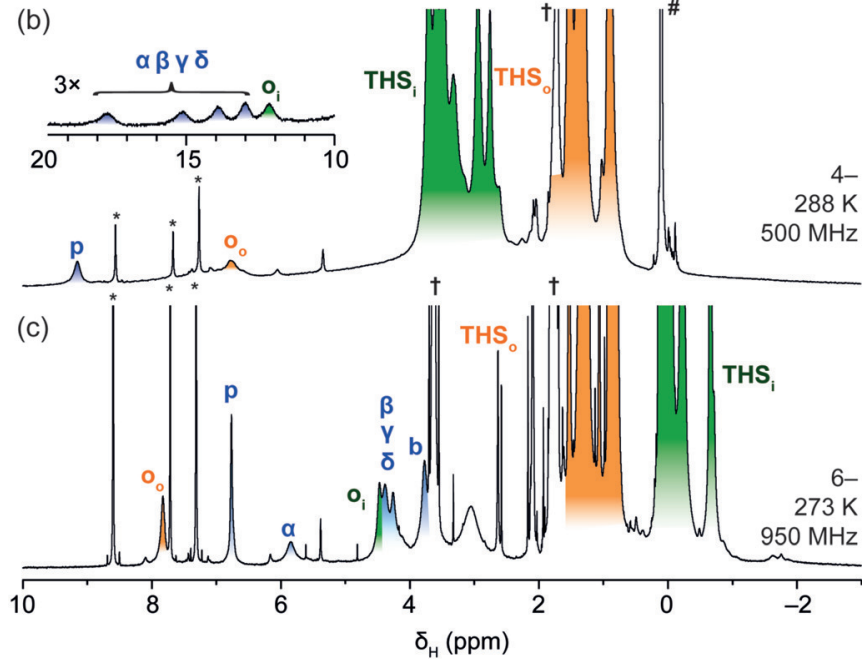

Figure 3. 'H NMR spectra of $c$-P6.T6 in its a) neutral, b) $4-$, and c) $6-$ oxidation states. (THS $=$ trihexylsilyl. Known impurities and solvent signals are labeled: * pyridine; $\uparrow$ THF; \# silicone grease. Full-scale spectra are shown in Figure S6 of the Supporting Information. We did not observe any field dependence in the chemical shifts other than slight shifts associated with chemical exchange processes.)

spectrum of template-free $\boldsymbol{c}$-P6 ${ }^{\mathbf{6}-}$ (see Figure S8). The resonances of the meso-aryl protons $\left(o_{\mathrm{i}}, o_{\mathrm{o}}\right.$, and $\left.p\right)$ are each related by a ${ }^{4} J$ scalar coupling, and so exhibit a characteristic coupling pattern in the ${ }^{1} \mathrm{H}$ TOCSY spectrum (see Figure S9). NOE correlations between the template protons and $o_{\mathrm{i}}$ permit the assignment of the latter, and further NOE correlations to the THS manifold centered around $-0.5 \mathrm{ppm}$ confirm its assignment as $\mathrm{THS}_{\mathrm{i}}$ (see Figure S11). THS ${ }_{\mathrm{o}}$ and $o_{\mathrm{o}}$ are related by NOE correlations, and $p$ can then be assigned by elimination. Although the $\mathrm{THS}_{\mathrm{i}}$ resonance is shielded by the global aromatic ring current, the $\mathrm{THS}_{\mathrm{o}}$ resonance is at the same chemical shift as for the neutral ring because these protons sit at the border between the shielding and deshielding regions of the chemical-shift-anisotropy cone (see Figure S2). The chemical-shift difference between resonances on the inside and outside of the nanoring, $\Delta \delta$, gives a measure of global (anti)aromaticity. For $\boldsymbol{c}$-P6.T6 ${ }^{\mathbf{6}-}, \quad \Delta \delta_{\mathrm{o}}=-3.35 \mathrm{ppm}$, and $\Delta \delta_{\mathrm{THS}, \mathrm{CH} 3}=-1.18 \mathrm{ppm}$. These values are approximately 1.75 times higher than those for the aromatic hexacation, $c$ P6. $\mathbf{T 6}^{6+}{ }^{6}{ }^{[13]}$ thus suggesting that the hexaanion has a stronger global diatropic ring current than the hexacation.
The spectrum of the 4- oxidation state is much broader than that of the 6- state, which made it impossible to record useful 2D ${ }^{1} \mathrm{H}$ TOCSY and ${ }^{1} \mathrm{H}-{ }^{13} \mathrm{C}$ HSQC spectra of $\boldsymbol{c}$-P6.T6 $\boldsymbol{6}^{\mathbf{4}}$, but NOESY spectra provided valuable correlations. The $\mathrm{THS}_{\mathrm{o}}$ resonance is readily assigned, since it is unperturbed by global (anti)aromaticity. It can then be seen that the $\mathrm{THS}_{\mathrm{i}}$ resonance is deshielded (appearing at ca. 3-4 ppm), consistent with global antiaromaticity. NOEs between $\mathrm{THS}_{\mathrm{i}}$ and $o_{\mathrm{i}}$, and between $\mathrm{THS}_{\mathrm{o}}$ and $o_{\mathrm{o}}$, permit the assignment of the signals for the ortho hydrogen atoms (see Figure S17). Both THS resonances also have equal-intensity NOEs to the $p$ resonance. The $\alpha-\delta$ template resonances at $13-17 \mathrm{ppm}$ were identified by comparing the spectra of $\boldsymbol{c}$-P6.T6 $\mathbf{6}^{\mathbf{4}}$ and template-free $\boldsymbol{c}$-P6 ${ }^{4-}$ (Figure $3 \mathrm{~b}$; see also Figure S16); the extreme deshielding of these protons supports the assignment of antiaromaticity.

The energy barrier for rotating one porphyrin subunit by $180^{\circ}$ in the template-free $\boldsymbol{c}$-P6 nanoring (swapping $\mathrm{THS}_{\mathrm{i}}$ and $\mathrm{THS}_{\mathrm{o}}, o_{\mathrm{i}}$ and $o_{\mathrm{o}}$ ) is very sensitive to the oxidation state. The transition state for this process must break the $\pi$-conjugation, so the barrier provides a probe for the enhanced resonance energy in charged species. In neutral $\boldsymbol{c}$-P6, rotation of porphyrin units is fast at room temperature. Upon cooling, the $o_{\mathrm{i}} / o_{\mathrm{o}}$ resonances separate and enter the slow exchange regime, with a coalescence temperature $T_{\mathrm{c}}$ of $200-203 \mathrm{~K}$, corresponding to a barrier of $(38.0 \pm 0.5) \mathrm{kJ} \mathrm{mol}^{-1}$ (see Figure S22). EXSY experiments on $\boldsymbol{c}$-P6 ${ }^{6-}$ at $228 \mathrm{~K}$ revealed a rotation barrier of $(50.2 \pm 0.5) \mathrm{kJ} \mathrm{mol}^{-1}$ (see Figure S25 and Table S4), which is similar to that previously measured for $c$ $\mathbf{P 6}^{\mathbf{6}+}\left((49.5 \pm 0.4) \mathrm{kJ} \mathrm{mol}^{-1}\right.$ at $\left.213 \mathrm{~K}\right)$.

In conclusion, we have shown that $[90 \pi]$ aromatic and $[88 \pi]$ antiaromatic anions can be generated by chemical reduction of a six-porphyrin nanoring of diameter $2.5 \mathrm{~nm}$ using decamethylcobaltocene. This approach to establishing global (anti)aromaticity is probably applicable to many other redox-active $\pi$-conjugated macrocycles and provides a useful complement to chemical oxidation. Since larger aromaticring-current effects are observed by NMR spectroscopy for $c$ P6. $\mathbf{T 6}^{6-}$ than for $\boldsymbol{c}$-P6.T6 ${ }^{6+}$, reduction may prove more useful than oxidation for establishing global aromaticity in even larger macrocycles. Aromatic macrocycles with diameters on the order of $10-20 \mathrm{~nm}$ are expected to show mesoscale magnetic properties, such as a nonlinear dependence of the induced ring current on the applied magnetic field, similar to that observed in mesoscopic metal rings. ${ }^{[28]}$

Cartesian coordinates for computational structures are available in the Supporting Information and from https://doi. org/10.6084/m9.figshare.9405308.

\section{Acknowledgements}

We thank the Oxford Advanced Research Computing facility and the Australian government-supported National Computational Infrastructure (NCI) for computational support and the EPSRC (grants EP/M016110/1, EP/J007161/1, and EP/ N017188/1) and ERC (grant 320969) for funding. M.D.P. additionally acknowledges a UNSW Scientia Fellowship. We thank Prof. Christina Redfield (Oxford Biochemistry) for 
access to the $950 \mathrm{MHz}$ NMR spectrometer, the Wellcome Trust, the EPA Trust, and the John Fell Fund for funding an upgrade to this spectrometer, and Prof. Jose Goicoechea (Oxford Chemistry) for advice on reduction experiments.

\section{Conflict of interest}

The authors declare no conflict of interest.

Keywords: anions · annulenes - aromaticity $\cdot$ macrocycles · porphyrinoids

How to cite: Angew. Chem. Int. Ed. 2019, 58, 15717-15720 Angew. Chem. 2019, 131, 15864-15867

[1] a) R. Gleiter, G. Haberhauer, Aromaticity and Other Conjugation Effects, Wiley-VCH, Weinheim, 2012; b) T. M. Krygowski, M. K. Cyrañski, Z. Czarnocki, G. Häfelinger, A. R. Katritzky, Tetrahedron 2000, 56, 1783 - 1796.

[2] a) H. J. Dauben, J. D. Wilson, J. L. Laity, J. Am. Chem. Soc. 1969 91, 1991 -1998; b) J. A. N. F. Gomes, R. B. Mallion, Chem. Rev. 2001, 101, 1349 -1383; c) P. Lazzeretti, Prog. Nucl. Magn. Reson. Spectrosc. 2000, 36, $1-88$.

[3] a) L. Pauling, J. Chem. Phys. 1936, 4, 673-677; b) K. Lonsdale, Proc. R. Soc. A 1937, 159, 149-161.

[4] M. Rosenberg, C. Dahlstrand, K. Kilså, H. Ottosson, Chem. Rev. 2014, 114, 5379-5425.

[5] D. Ajami, O. Oeckler, A. Simon, R. Herges, Nature 2003, 426, $819-821$.

[6] A. I. Boldyrev, L.-S. Wang, Chem. Rev. 2005, 105, 3716-3757.

[7] a) E. Hückel, Z. Phys. 1931, 70, 204-286; b) W. von E. Doering, F. L. Detert, J. Am. Chem. Soc. 1951, 73, 876-877.

[8] R. Breslow, Acc. Chem. Res. 1973, 6, 393-398.

[9] N. Toriumi, A. Muranaka, E. Kayahara, S. Yamago, M. Uchiyama, J. Am. Chem. Soc. 2015, 137, 82-85.

[10] M. Hoffmann, C. J. Wilson, B. Odell, H. L. Anderson, Angew. Chem. Int. Ed. 2007, 46, 3122-3125; Angew. Chem. 2007, 119 3183-3186.

[11] G. Karunanithy, A. Cnossen, H. Müller, M. D. Peeks, N. H. Rees, T. D. W. Claridge, H. L. Anderson, A. J. Baldwin, Chem. Commun. 2016, 52, 7450-7453.

[12] P. Kowalska, M. D. Peeks, T. Roliński, H. L. Anderson, J. Waluk, Phys. Chem. Chem. Phys. 2017, 19, 32556-32565.

[13] a) M. D. Peeks, T. D. W. Claridge, H. L. Anderson, Nature 2017, 541, 200-203; b) M. Rickhaus, M. Jirasek, L. Tejerina, H. Gotfredsen, M. D. Peeks, R. Haver, H.-W. Jiang, T. D. W. Claridge, H. L. Anderson, ChemRxiv preprint 2019, https://doi. org/10.26434/chemrxiv.8953565.

[14] N. C. Baird, J. Am. Chem. Soc. 1972, 94, 4941-4948.

[15] M. D. Peeks, J. Q. Gong, K. McLoughlin, T. Kobatake, R. Haver, L. M. Herz, H. L. Anderson, J. Phys. Chem. Lett. 2019, 10, $2017-$ 2022.
[16] a) S. Saito, A. Osuka, Angew. Chem. Int. Ed. 2011, 50, $4342-$ 4373; Angew. Chem. 2011, 123, 4432-4464; b) Y. M. Sung, M.-C. Yoon, J. M. Lim, H. Rath, K. Naoda, A. Osuka, D. Kim, Nat. Chem. 2015, 7, 418-422; c) T. Yoneda, T. Soya, S. Neya, A. Osuka, Chem. Eur. J. 2016, 22, 14518-14522; d) T. Tanaka, A. Osaka, Chem. Rev. 2017, 117, 2584-2640.

[17] W.-Y. Cha, T. Kim, A. Ghosh, Z. Zhang, X.-S. Ke, R. Ali, V. M. Lynch, J. Jung, W. Kim, S. Lee, S. Fukuzumi, J. S. Park, J. L. Sessler, T. K. Chandrashekar, D. Kim, Nat. Chem. 2017, 9, $1243-$ 1248.

[18] H. Gregolińska, M. Majewski, P. J. Chmielewski, J. Gregoliński, A. Chien, J. Zhou, Y.-L. Wu, Y. J. Bae, M. R. Wasielewski, P. M. Zimmerman, M. Stępień, J. Am. Chem. Soc. 2018, 140, 1447414480 .

[19] X. Lu, T. Y. Gopalakrishna, H. Phan, T. S. Herng, Q. Jiang, C. Liu, G. Li, J. Ding, J. Wu, Angew. Chem. Int. Ed. 2018, 57, 1305213056; Angew. Chem. 2018, 130, 13236-13240.

[20] G. Li, T. Y. Gopalakrishna, H. Phan, T. S. Herng, J. Ding, J. Wu, Angew. Chem. Int. Ed. 2018, 57, 7166-7170; Angew. Chem. 2018, 130, $7284-7288$.

[21] S. Dong, T. Y. Gopalakrishna, Y. Han, C. Chi, Angew. Chem. Int. Ed. 2019, 58, 11742-11746; Angew. Chem. 2019, 131, 1186811872 .

[22] J. K. Sprafke, D. V. Kondratuk, M. Wykes, A. L. Thompson, M. Hoffmann, R. Drevinskas, W.-H. Chen, C. K. Yong, J. Kärnbratt, J. E. Bullock, M. Malfois, M. R. Wasielewski, B. Albinsson, L. M. Herz, D. Zigmantas, D. Beljonne, H. L. Anderson, J. Am. Chem. Soc. 2011, 133, 17262-17273.

[23] a) W. Huber, K. Müllen, O. Wennerström, Angew. Chem. Int. Ed. Engl. 1980, 19, 624-625; Angew. Chem. 1980, 92, 636-637; b) K. Müllen, H. Unterberg, W. Huber, O. Wennerström, U. Norinder, D. Tanner, B. Thulin, J. Am. Chem. Soc. 1984, 106, 7514-7522; c) K. Müllen, Chem. Rev. 1984, 84, 603-646.

[24] a) P. von R. Schleyer, C. Maerker, A. Dransfeld, H. Jiao, N. J. R. van E. Hommes, J. Am. Chem. Soc. 1996, 118, 6317-6318; b) Z. Chen, C. S. Wannere, C. Corminboeuf, R. Puchta, P. von R. Schleyer, Chem. Rev. 2005, 105, 3842-3888.

[25] a) R. Herges, D. Geuenich, J. Phys. Chem. A 2001, 105, $3214-$ 3220 ; b) D. Geuenich, K. Hess, F. Köhler, R. Herges, Chem. Rev. 2005, 105, 3758-3772.

[26] N. G. Connelly, W. E. Geiger, Chem. Rev. 1996, 96, 877-910.

[27] J. Rawson, P. J. Angiolillo, M. J. Therien, Proc. Natl. Acad. Sci. USA 2015, 112, 13779-13783.

[28] a) N. A. J. M. Kleemans, I. M. A. Bominaar-Silkens, V. M. Fomin, V. N. Gladilin, D. Granados, A. G. Taboada, J. M. García, P. Offermans, U. Zeitler, P. C. M. Christianen, J. C. Maan, J. T. Devreese, P. M. Koenraad, Phys. Rev. Lett. 2007, 99 , 146808 ; b) A. C. Bleszynski-Jayich, W. E. Shanks, B. Peaudecerf, E. Ginossar, F. von Oppen, L. Glazman, J. G. E. Harris, Science 2009, 326, 272-275.

Manuscript received: July 19, 2019

Accepted manuscript online: August 9, 2019

Version of record online: September 17, 2019 